\title{
Landscapes of memory: a practice theory approach to geographies of memory
}

\author{
G. Maus \\ Department of Geography, Christian-Albrechts-Universität zu Kiel, Ludewig-Meyn-Str. 14, \\ 24098 Kiel, Germany \\ Correspondence to: G. Maus (maus@geographie.uni-kiel.de)
}

Received: 3 November 2014 - Revised: 13 August 2015 - Accepted: 25 August 2015 - Published: 1 September 2015

\begin{abstract}
Conceptualised from a practice theory perspective, "landscape" can be employed as an overarching term encompassing otherwise divergent perspectives within geographies of memory: landscape of memory can denote social practice, meaningful materiality, individual experience, and collective imaginations as constituent of localised memory. Using Theodore Schatzki's practice theory, landscapes of memory are described as a social phenomenon: practices of memory contextualise certain places as meaningful in relation to the past. In turning to small Cold War munitions bunkers, by way of example, it is demonstrated how this perspective broadens the scope of geographies of memory to include everyday practices and their relation to collective memories.
\end{abstract}

\section{Introduction}

From a geographical perspective, material patterns or outcomes of remembrance, social processes of remembering, and the actors involved in memory work are all worthwhile subjects of investigation. When I got interested in how historical places of Cold War history were enacted by different actors, I soon asked myself through which actions a specific object or place is actually rendered a relic of the Cold War. What is it that heritage authorities, enthusiasts or others $d o$ that establishes concrete bunkers as a relic in a memorial landscape? During fieldwork it soon became obvious that monument protection authorities, bunker-hunters, and geocachers all conceived of relics in a similar way and even engaged with these structures through relatively homogenous actions - although many actors would not think of themselves as being involved in memory work.

In this paper I want to deepen an understanding of how modes of producing a cultural memory (Assmann, 2011) may be conceived of as not only pertaining to national politics of remembering and management of heritage sites. By disengaging common biases in geographies of memory that tend to emphasise either the materiality or praxis of remembrance as well as conceiving of memory as either a social phenomenon or an individual capacity (Sect. 2), I want to turn attention to place-bound memory-making. I suggest that practice theory, which has been advocated in human geography as a means to turn attention to mundane practices (Everts et al., 2011), can accommodate these tensions and theorise them within a common social ontology (Sect. 3). Specifically, Theodore Schatzki's (2012) vocabulary can be employed to analyse landscapes of memory by conceiving of them as a social phenomenon. While both terms - "landscape" and "memory" - suggest a holistic approach, when conceptualised in a practice framework, they are suitable to describe (rather than explain) activities that have often been overlooked. These can be labelled practices of localised memory. They are routinised actions or sets of particularly organised "doings and sayings" (Schatzki, 1996:88-90) that contextualise certain places as relics of a time past.

In looking at a specific type of small munitions bunkers that were part of a now obsolete Cold War defence system in Germany (Sect. 4), I will show how heritage professionals, bunker-hunters, and geocachers explicitly and implicitly contribute to a landscape of memory of that era. While their activities are easily discernible as different practices, they all share certain aspects that connect them as practices of localised memory.

In conclusion (Sect. 5), I argue that the thorough vocabulary borrowed from practice theory offers a promising path in geographies of memory to analyse explicit and implicit mem- 
ory work beyond approaches that focus on actors or meanings alone. In looking at how memory is actually practised, and analysing the social phenomena these practices constitute, geographers can broach the issue of memory-making in unlikely or inconspicuous fields of investigation and broaden our understanding of localised social memories.

\section{Geography, memory, and landscape}

Geographies of memory (Foote and Azaryahu, 2007) have proliferated during the past decade. Geographers have dwelt on places of memory, memorial landscapes, national remembrance, or private recollection. Among this body of work are detailed analyses of memory conflicts in public space (Till, 2003; Hoelscher and Alderman, 2004), the legibility of memorial landscapes (Ogborn, 1996; Johnson, 2005), the significance of personal memories for becoming in spaces and places (Bischoff and Denzer, 2009; Jones and Garde-Hansen, 2012), and the concept of forgetting (Legg, 2007). With a range of edited collections (Meusburger et al., 2011; Jones and Garde-Hansen, 2012) and special issues (Hoelscher and Alderman, 2004; Rose-Redwood et al., 2008; Zeitler, 2009; Bischoff and Denzer, 2009) in place, the genre of geographies of memory can be considered as firmly established within cultural geography.

In this work, geographers have often "presumed to isolate memory as a discreet object of study, as if memory exists apart from our attempts to know it" (Hoskins, 2012:246). When looking at the approaches geographies of memory have devised, two tensions become apparent (cf. Fig. 1).

The first tension is the question of whether the analysis of memory should be based on material or spatial markers of memory or on the social practice(s) of remembering. Often, places and spaces feature as material media of recollection that are interpreted as sites of symbolic meaning. The power of toponymic inscriptions, for instance, has been described as city-text (Azaryahu, 1996) or places as markers of past events which have, more broadly, been framed as places of memory (Till, 2003). Things have been considered as "a place of artifactual identification with the past" (DeLyser, 1999:624) that may evoke multiple sensations, feelings, and indeed, memories (cf. Edensor, 2005). While these approaches highlight material markers of memory, others foreground the praxis of remembering: commemorative rituals can be thought of as constituting spaces of remembrance (Petermann, 2011), or engagements with the city as in urban exploration can have the quality of "assaying history", i.e. a construction of narrative through personal interaction with a place (Garrett, 2011).

The second tension I want to point to concerns conceptualisations of memory as either an individual property or as a collective phenomenon. Terms like "cultural arena" (Alderman, 2002) or "places of memory" (Till, 2003) demonstrate how group identities, power relations, and memory are produced spatially. They refer to collectively shared memories

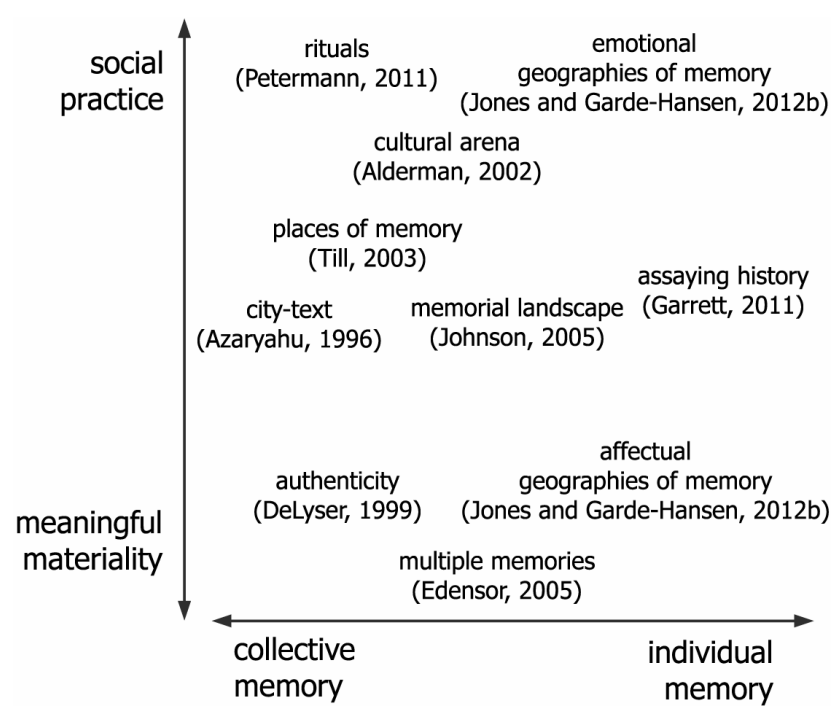

Figure 1. Conceptual tensions within geographies of memory. The position in the matrix corresponds with the approaches' principal concerns (own figure).

of nations, minorities or other groups. More recently, personal recollections, grief, and trauma or, in a broader sense, embodied, emotional, and affectual memories have come into view (cf. Jones and Garde-Hansen, 2012).

Figure 1 positions these approaches within geographies of memory according to their main target within this matrix of tensions as I understand it. Unsurprisingly, potentially holistic terms like "place" and "landscape" belong to those approaches that thrive to accommodate all of these dimensions. While the term "places of memory" often refers to Nora's (1989) notion of lieux de mémoire (cf. Legg, 2005), geographers like Lowenthal (1975) or historians such as Schama (1995) use the term "landscape" in conjunction with memory to describe geographical imaginations of the pastness of our world. This mirrors the anglophone tradition of "landscape as both material entity and symbolic meaning, as both persistent in form and changeable in meaning, and thus as a key site for conflicts over memory, identity and justice" (Wylie, 2007:193). Johnson (2005:173), for instance, argues that a memorial landscape should be thought of as a stage that acts "not solely as the backdrop in which the action takes place but as actively constituting the action. The stage acts more than the context for the performance - it is the performance itself."

Although it remains unclear in Johnson's (2005) case what landscape as a stage contains, what kind of actions it entails, and how this performance is social, I believe that "landscape" is an appropriate term to sketch the socio-spatial phenomenon that is in question here. This corresponds with practice-informed views of landscape as a way of seeing (Cosgrove, 1998) or a place of human dwelling (Ingold, 2000). Landscape, Dwyer and Alderman (2008) argue, is 
applied in metaphorical ways in geographies of memory: as semiotic texts, as cultural arenas, and as constituted in commemorative performances. These metaphors help to describe the tension between memory as represented in both meaningful materialities and social practice, but as a concept they remain unspecific. Moreover, in cultural geography, "landscape" has been frequently criticised as a static and ideographic idea (e.g. Cresswell, 2003) - while, at the same time, memory has been a strong focus in landscape research (Mitchell, 2003:790).

This critique of an ambiguous use of the term "landscape" applies to the usage of "memory" as well. Referring to memory studies as a whole, Confino (2008:79) observed that "the notion of memory" has been "more practiced than theorised" and Erll (2008:3) adds that there is a need for "a very sensitive handling of terminology" in memory studies in order to facilitate interdisciplinary exchange. So, rather than using "landscape" and "memory" loosely as umbrella terms circumscribing a broad interest in memory and space, I suggest making use of these terms as part of the vocabulary of a rigid social ontology.

\section{Practice theory and landscapes of memory}

Practice theory according to Schatzki (1996, 2002, 2010b, cf. 2012 for a brief introduction) can serve this purpose: it puts human activity as observed individually centre stage by conceiving of it as embedded in social practices, while also taking physical situations into account as material arrangements. Schatzki's "site ontology derived from practice theory works towards a dynamic and activity-oriented understanding of space and place" (Everts et al., 2011:327). It is to be seen alongside other cultural theories like Bourdieu's (1977) theory of practice, Giddens' (1984) structuration theory, and non-representational theory (Thrift, 2008) that all prioritise praxis as central to sociality (rather than e.g. ideas in textual theories, cf. Reckwitz, 2002).

Schatzki's ontological vocabulary, however, can be put to use as an analytic method, as I will show in Sect. 4. In his view, places and things gain meaning through human activity that is organised in routinised social practices. Practices are action complexes that are easily understood as such, even by outsiders to a specific social practice. For memory studies, practices that explicitly engage with the past, like monument protection, curating a museum exhibition, or historical research, immediately spring to mind as potential objects of study. Schatzki's vocabulary can be used to describe such practices of memory systematically.

According to Schatzki (1996:88-130), any social practice consists of routinised "doings and sayings" that share a specific organisational structure. Four concepts help to narrow down this organisation of a practice: they are (a) a practical understanding or knowledge of where and how to perform certain tasks, (b) a teleoaffective structure that suggests which tasks are necessary or emotions appropriate to achieve an end, (c) possibly explicit rules that have a binding capacity on how to do something and (d) general understandings that are expressed in a number of practices and can thus be likened to cultural dispositions.

Since these basic terms are directed at explaining the social character of practices, in geography of memory, those practices that contribute to a social phenomenon of memory have to be identified. In this study, I understand practices of memory as those routinised doings and sayings that produce collective memories in the sense of "collectively shared representations of the past" (Kansteiner, 2002:181). While Schatzki (2010b:201-221) is interested in the evolution of practices through memory as occurring within a collective framework that ultimately brings about group identities (an idea dating back to Halbwachs, 1980 [1925]; cf. Middleton and Brown, 2011), I want to put his theory in dialogue with the notion of cultural and communicative memories. Assmann (2011) distinguishes cultural memory as a cognisant practice of memory that is highly formal, mediated in symbolic forms and performances, and conducted by specialist carriers from communicative memory, i.e. a social mode of memory based on oral tradition. Schatzki's vocabulary opens a path to analyse cultural memories and their making: memory, then, is performed in organised "doings and sayings" by individuals - which resembles Assmann's conception of "formal" performance and "specialist carriers" of cultural memory.

In this view, practices of localised memory contextualise their human carriers - those performing the actions that make up a practice - and the physical world they engage with as material arrangements. For Schatzki (2002:101), these "arrangements of people, artifacts, organisms, and things" represent a snapshot of the world in a specific situation. Social practices "effect, alter, use, and are directed toward or inseparable from arrangements while arrangements channel, prefigure, and facilitate practices" (Schatzki, 2015:6). When describing social phenomena as practice arrangement bundles, these can only exist as long as the practices producing them are still performed. This coincides with Assmann's (2011:18-19) conception of cultural memory as being fostered through continuous performance.

I suggest describing the social production of localised cultural memories as landscapes of memory. Schatzki (2010b:97-106, 2011) does indeed offer a conception of landscape that is not a way of seeing, but consists of that which is seen. It encompasses "a portion of the greater world around that can be taken in visually where human activity takes place" (Schatzki, 2011:79). This conception conceives of landscape as a topographic cutting from the world that exists and is perceived only in the conduct of social practices centred on vision. I argue that this notion of landscape can be replaced with practices that are centred on place-specific representations of the past, i.e. practices of localised memory. 
Let me illustrate this idea using public monument protection as an example. The work of civil servants in heritage authorities can be seen as a well-defined social practice: through taking photos, noting architectural details, and evaluating a set of criteria for listing a building, a material structure is contextualised as something meaningful: a historical monument. In my view, this practice works toward, and is constituted by, a social phenomenon of numerous related practices that constitute landscapes of memory. The spatial implications of such a lived landscape are twofold.

Firstly, a landscape of memory is an imaginative geography. The practice of monument protection arranges people and artefacts in a meaningful way: an individual historical monument cannot, in this practice, be thought of independently from the entirety of listed buildings. In Schatzki's terminology this imaginative geography can be described as an arrangement that corresponds with commemorative culture.

Secondly, landscapes of memory can be thought of as a relational space. The arrangements associated with practices of memory anchor (Schatzki, 2010b:73) commemorative meanings at specific places. Other practices that use or in some way impact the same objects likely do not constitute a landscape in this sense: practices like care-taking or building do not rely on encountering landscapes of memory. They are directed at managing, cleaning up or erecting a building. However, I argue, other practices beyond that of monument protection will relate to and contribute to the same landscape of memory (Sect. 4.2).

In sum, a landscape of memory consists of several bundles of practices of memory and their corresponding commemorative arrangements. It is an abstract conception of the pastness of our world that is constituted in routinised practices of localised memory and anchored at specific places. This conception equips geographers with the tools to analyse a range of empirical phenomena as to whether they contribute to a commemorative understanding of certain places by looking into the organisational structure of social practices. Figure 2 refers back to Fig. 1 and the tensions in geographies of memory - actions carried out by individual carriers of practices - are organised socially. Materiality, on the other hand, is arranged meaningfully in commemorative arrangements that are effective beyond the reach of individual actors, while, in specific situations, things exhibit a certain "usability" within practices of remembering. While Schatzki's vocabulary is inherently holistic, here, it is positioned as a method for description and analysis. It allows fields contributing to cultural memories, beyond those that do so explicitly, to be embraced.

\section{Analysing landscapes of memory}

Concepts of social practices share an "affinity to the observable and to empirical methods of observation" (Schmidt and Volbers, 2011:420). The organisation of a practice, however, cannot be observed as such. "This is detailed information that

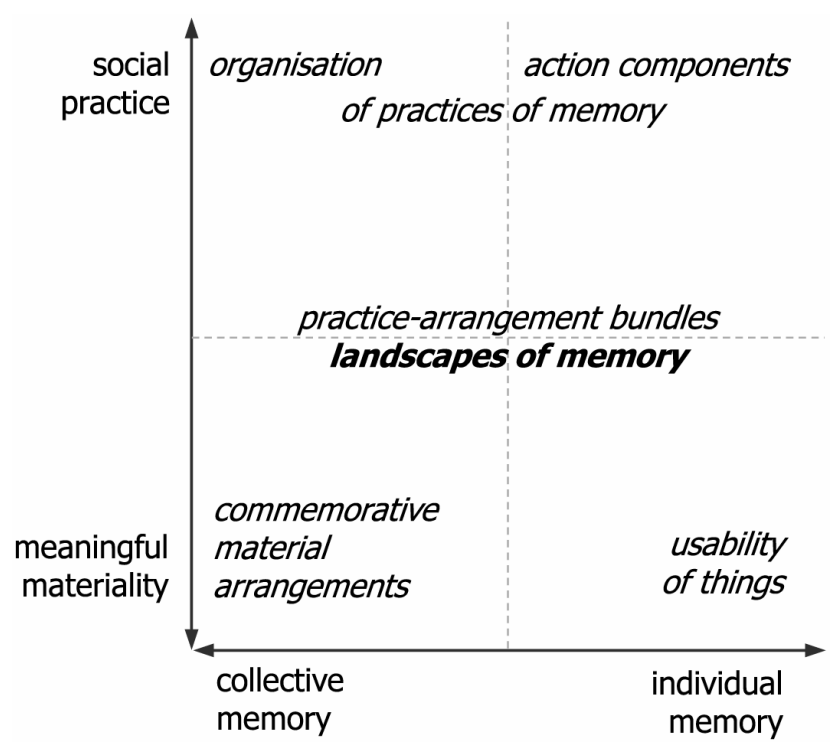

Figure 2. Mapping landscapes of memory as seen through the vocabulary of Schatzki's practice theory on conceptual tensions within geographies of memory (own figure).

no one, including the subjects, possesses [...]. To acquire this knowledge, the investigator has no choice but to do ethnography, that is, to practise interaction-observation" (Schatzki, 2012:24). How practice theory should be operationalised is, however, rarely discussed. Hitchings (2012), argues that people can indeed reflect their practices e.g. in interviews. In my project on landscapes of memory of the Cold War, I used a broad ethnographic approach which included narrative interviews, participant observation, ethnographies of internet forums, focus group discussions, and document analysis, in an effort to reconstruct practices of memory (Maus, 2015). Fieldwork was undertaken between 2012 and 2014 in the north of Germany and in an area in central Germany referred to as the Fulda Gap during the Cold War, and focussed on relics of Cold War militarisation in the West. I carried out analysis of this ethnographic material in two steps. First, the material was organised and presented in a realistic representation of observations typical of many ethnographies (cf. Crang and Cook, 2007). Second, this was followed by a more formal analysis using Schatzki's vocabulary. I refer to this as a functional reconstruction of commemorative arrangements and corresponding practices of memory because it is directed at those organisations these practices share and thus at how they correspond with each other.

\subsection{Practices of localised memory and commemorative arrangements}

With the 25th anniversary of the fall of the Berlin Wall just behind us, the Cold War era is increasingly historicised. Arguably, as a recent period, it is not yet thoroughly established in memory culture as the Holocaust or the history of World 

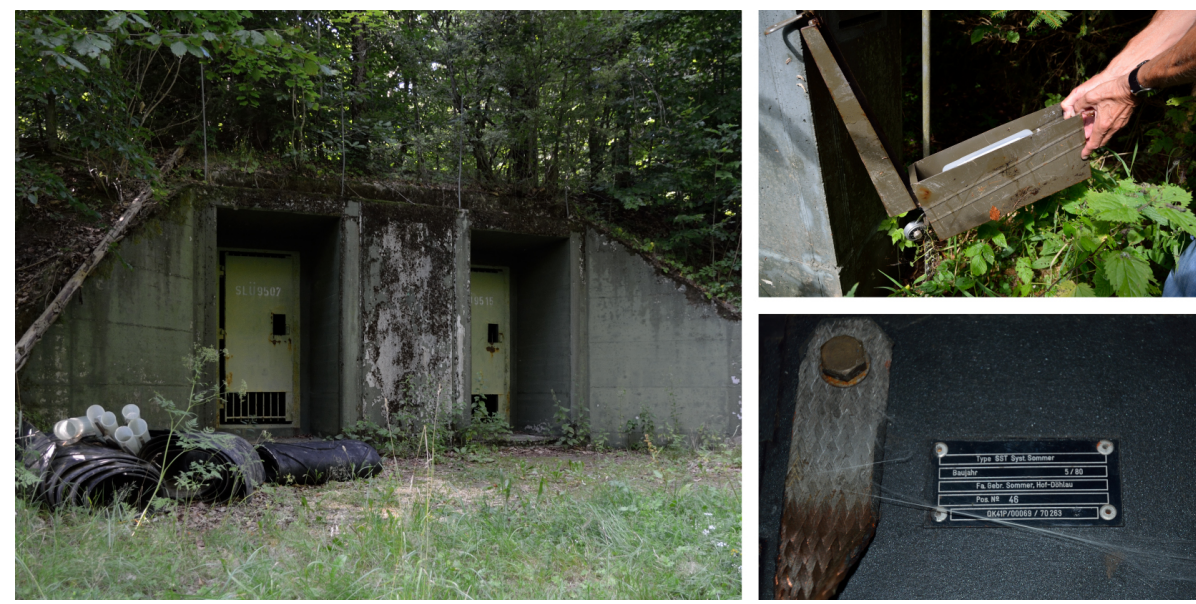

Figure 3. Bunker complex for demolition material intended for preconstructed obstacles; a geocache in an old ammunition box chained to a lightning rod on a bunker ventilation shaft and a manufacturing label on a blast-proof door (clockwise, own photographs).

War II. In Germany, politics of remembrance of the Cold War largely concern the sites of injustice in the German Democratic Republic (GDR) and German division (cf. Kaminsky, 2007). Recently, however, relics of Cold War militarisation in the former West, like military establishments, civil defence bunkers, and similar structures, have been identified as relics of the Cold War. This broadens public understanding of which places are to be seen as constituting a landscape of memory of the Cold War.

Here, I want to turn to a peculiar material aspect of Cold War history: a specific kind of small munitions bunkers (Fig. 3) that belonged to a system of so-called preconstructed obstacles that were prepared in strategic lines of defence roughly parallel to the Iron Curtain (cf. Department of the Army, 1985:130-135). These included shafts sunk into roads and bridges equipped with demolition chambers to be blown up quickly in case of hostilities to protract an expected attack from the East. The small munitions bunkers were built a few hundred metres to several kilometres away from the obstacles and held demolition material earmarked for each site. They were used for storage of up to 5 tons of explosives and other material such as detonation cord and blasting caps. When not situated within military munitions depots, these officially secret bunkers were usually built in state forests, for anyone rambling in the woods to see. Although holding substantive amounts of explosives, they were not guarded but regularly checked by Wallmeister personnel who also maintained the obstacle system. The demolition material was stored in a small chamber protected by three massive, blast-proof steel doors. State monument protection officers and enthusiast bunker-hunters have, perhaps unsurprisingly, paid some attention to these structures. The leisure activity of geocaching, however, has actually made the positions of most of these bunkers accessible to the public while engaging with the structures themselves in a different way.
As suggested above, public monument protection can be considered a fairly straight example of a social practice. It features a hierarchically organised structure of individual projects like monument assessment, designation, and conservation in order to meet the ultimate end of preserving historical buildings. The laws and regulations governing monument protection make for an exceptionally high degree of normative rules organising the practice. Most German statelevel monument protection acts, for instance, require a historic monument to belong to a past era and to be of historical, scientific, technological, or urbanistic importance and determine the authorities' responsibilities (cf. Hubel, 2011). Across former West Germany, state authorities have listed a range of nuclear bunkers, public shelters, military listening posts, and, also, preconstructed obstacles associated with the era of the Cold War. It is part of the practical understanding of monument assessment that it is conducted in a manner which abides by scholarly standards. This is evident from publications and by the rules set out in law. A professional report on assessment methods for "Cold War fortifications", for example, represents the assessment and designation of Cold War preconstructed obstacles as a predominantly scientific enterprise (cf. Ongyerth, 2009): tables of the objects in question have to be compiled, age, rareness, and conspicuousness need to be evaluated, and the bunkers' locations are plotted in a geographical information system. The ultimate result of this work are short entries in the state registers of historical monuments: "Two munitions bunkers at Beselberg, munitions bunker AS-9511 and AS-9512 for the storage of demolition material for the case of defence, 1970, abandoned in 1993" (BLfD, 2014, my translation).

Although the ultimate end of state monument protection - to evaluate whether material objects should be worthy of conservation - is well documented and obvious to participants and observers, many actions that are part of the practice are not discussed in textbooks on monument protection. 
Their interpretation is, however, essential to further establish the organisation of that practice. For example, in one focus group discussion, a senior state conservator argued that Cold War monuments were of general interest to her administration, but limited resources and the political environment did not allow for speedy and substantial designation of Cold War monuments. Political feasibility is as much a part of the practical understanding of designation as the knowledge of Cold War structures is for assessment of the bunkers. The latter is a further issue, as another conservator argued: the sheer abundance of Cold War structures is difficult to handle. It poses a threat to the practical understanding of how to conduct a thorough consideration of all buildings of one kind in order to select only the most suitable for statutory protection simply because there are too many to actually visit them in person - given his administration's present resources.

Examining an individual building is one of the tasks necessary within the project of assessing a building to the end of preserving a representative cross section of Cold War structures. I visited a number of munitions bunkers with a monument protection authority officer who exhibited a pronounced practical understanding of what was important to her as a conservator: she scanned blast-proof doors for manufacturer labels and noticed how different lightning rods were used at different bunkers - specifics that had escaped me on my previous visits to those sites.

Such thoroughness is a characteristic of a different yet similar practice conducted by enthusiasts. A group of bunkerhunters that meets in an online forum is dedicated to producing a register of all Cold War preconstructed obstacles, including the bunkers, across West Germany as of the late 1980s. As participants in bunker-hunting, they exhibit a similar practical understanding of how these structures should be registered that amounts to a set of unwritten rules: information on their number - usually up to six in a place exact location, a photograph, and contextual information on paths and roads in the vicinity is mandatory. Based on this information, group administrators can determine whether a newbie has actually discovered a munitions bunker or may have stumbled upon a water supply reservoir somewhere in the forest. Interestingly, the exact location of the bunkers is actually hidden from public access on the internet database.

Bennett (2013) has identified four modes of representation among bunker-hunters that can be summarised as political, taxonomic, nostalgic, and experiential encounters with a bunker. From a practice theory perspective, these modes describe not only how these places become intelligible within bunker-hunting, but also which actions are intelligible in relation to these structures. A bunker is an important material entity within the commemorative arrangements discussed here. Similar to the way in which non-representational theory (Thrift, 2008) brings material agency to the front, practice theory acknowledges the affordances of materiality. Bunkers can be mapped, photographed, measured, explored, climbed, and so on. What these actions mean and in which practice they make sense, however, is dependent on the organisational structure of the practice as part of which these actions are performed. Ultimately, practice theory privileges social explanations at the expense of material agency (Schatzki, 2010a).

In addition to these organised actions, both practices also share similar ways of talking about the bunkers. In both conservation reports and forum discussion it is stated frequently that measures should be taken to preserve the bunkers as historical structures for generations to come. The small munitions bunkers are also perceived to be at threat from vandalism. While in monument protection this amounts to a careful evaluation whether to grant statutory protection or not, in bunker-hunting this is often met with the strategy not to disclose the exact location of vulnerable sites publicly. Speech acts, in other words, are integrated into the same teleoaffective structure and exhibit the same practical understandings specific to a practice.

Apparently, both monument protection and bunkerhunting share similar practical understandings that aim to interpret certain structures as evidence of a time past and, also, of how these should be handled properly. While this may amount to diverging meanings in the arrangement, e.g. concerning different views on which information is necessary to appreciate the bunker as a relic of the Cold War, the general idea of the bunker as a relic is similar in both practices. How the world is intelligible is articulated in the organisation of social practices (Schatzki, 1996:110-132). A specific understanding of the bunker as something of historical importance and worthy of protection is, then, a general understanding of commemorative culture that is articulated in practices that employ different practical understandings of how to act toward or with these structures in particular.

This becomes clear when looking at the material arrangements these practices constitute. In monument protection the bunker is part of an arrangement of people and things that is about cultural heritage, encompassing bunkers as heritage along with monument registers, regulations, publications, state conservators and other stakeholders. Yet in bunkerhunting, a bunker is contextualised as belonging to the past, too, but beyond heritage, it is intelligible as an amalgam of heritage, hobby, and identity, including the bunker as heritage - but possibly also as a former workplace - the online community members, their forum, photo cameras, and so on. It is important to recognise that the bunker is not the arrangement, but features as something different in relation to other entities within each practice arrangement bundle.

Table 1 summarises the arrangement that the practice of monument protection performs: it is a contextualisation of people and things that are made meaningful through organised doings and sayings. For an analysis of landscapes of memory, as introduced above, it is helpful to distinguish the meanings performed according to their spatial (imaginative geography) and commemorative notions. This schematic representation also facilitates comparison of separate cases, as the following section will show. 
Table 1. Arrangement of monument protection.

\begin{tabular}{l}
\hline Imaginative geography that features \\
\hline - historical structures as a resource \\
- protected structures as archives of the past \\
- planning as a conscious configuration of the past environment \\
\hline commemorative meaning \\
\hline - of the monument inventory as a representation of building culture \\
- of public interest in conservation of that building culture \\
- of designation as salvation of at-risk heritage \\
- of the monument as authentic evidence of the past \\
\hline by relational positioning and performative production of \\
\hline - monument protection officers, curators, their tools, \\
the built environment, monuments etc. \\
\hline
\end{tabular}

\subsection{Tracing memory beyond the heritage discourse}

Both monument protection and bunker-hunting can be accredited to "ideas about heritage and its management [..., which] were embraced so wholeheartedly by the public that it has become possible for us to speak of a late twentieth century heritage 'boom"' (Harrison, 2012:68). They subscribe to the heritage idea consciously. But what about other practices that are not explicitly about interpreting a world conceived of as strewn with relics of the past? I want to explore this question very briefly by turning to geocaching - a leisure activity that focuses on discovering places and collecting successful "finds" (O'Hara, 2008). Although there is a sub-genre of history caches and caches that highlight abandoned places, in geocaching, the bunkers become part of a game where players share special places in their home country. Usually the owner of a cache - i.e. the person hiding a small box somewhere for others to find via an internet platform, providing Global Positioning System (GPS) coordinates - does not offer any contextual information on the bunker. Instead, the bunkers are usually referred to as "lost places". This pseudoanglicism is used by German-speaking geocachers and urban explorers for all kinds of abandoned places that are experienced as exciting, thrilling and even uncanny places and is reminiscent of Edensor's (2005) discussion of the "ghosts" of ruins. However, in many cases, other players will contribute historical information in their "found-it" $\operatorname{logs}$, often referring to personal memories and their general knowledge of the military acquired when they were in service (Germany had a conscript army during the Cold War and up until recently).

As a rule of thumb, a geocache is hidden in the vicinity of each of the hundreds of small munitions bunkers that dot West German landscapes. As "lost places" the bunkers are concordant with monument protection and bunker-hunting framed as relics of a past, although the knowledge available to players in the game is notoriously partial, inaccurate or even plain wrong. However, when summarised as an arrangement of geocaching and questioned with a view to imagina-
Table 2. Arrangement of geocaching.

\begin{tabular}{l}
\hline Imaginative geography that features \\
\hline - geocaches as highlighted places in a landscape \\
- spaces of adventurous experiences (at places which are thrilling, \\
uncanny, beautiful etc.) \\
\hline commemorative meaning \\
\hline - of the (pseudo-)factual history of a place \\
- of personal recollections in conjunction with a place \\
- of geocaches as historical guides (in the case of history caches) \\
\hline by relational positioning and performative production of \\
\hline - geocachers and non-geocachers, cache boxes, logbooks, \\
pens, GPS devices, \\
- (hiding) places, internet platforms, etc.
\end{tabular}

tive geographies and commemorative meanings as above, the practice actually contextualises the bunkers in quite a similar way as monument protection does (Table 2).

Monument protection, bunker-hunting, and geocaching contextualise the bunkers as belonging to and being of the past. Although the bunkers are engaged with by different sets of routinised doings and sayings in those practices, they can all be described as practices of localised memory to the extent that they anchor an understanding of material structures as evidence of a time past at a specific place. While those actions are organised by different practical understandings of how to encounter a bunker (for instance by documenting it vs. experiencing it as a thrilling place to be), they exhibit a similar general understanding of the pastness of our world and of a respectful attitude toward things interpreted as heritage. This shared general understanding connects these practices as practices of memory and constitutes what I have described as a "landscape of memory" - a shared implicit conception of imaginative geographies that are explicitly (monument protection, bunker-hunting) or implicitly (geocaching) enmeshed with commemorative meanings and thereby contribute to the same social phenomenon.

\section{Conclusions}

The reconstruction of a landscape of memory as a social phenomenon, presented above, questions the rigid distinction Assmann (2011) draws between cultural memory as maintained by elites and communicative memory as dependent on lived experience. Although a practice like geocaching appears to have little to do with memory work at first glance, the approach based on practice theory can unveil such connections; a commemorative interpretation of material places, then, is indeed due to the performance of a shared general understanding of how the past is believed to be present. This is also the general understanding that makes practices of localised memory a social unity. 
For geographies of memory, the concept of landscapes of memory helps to put empirical biases into perspective: rather than choosing to pay attention to material markers of memory at the expense of praxis or to collective forms of memory at the expense of individual performances of memory and vice versa - it does not discriminate against any of these perspectives. Landscapes of memory subscribe to a dynamic understanding of memory and landscape and as such help to trace memory in mundane practices beyond elite claims to interpretation. In this view, bunker-hunting appears as a practice similar in teleoaffective structure to monument protection - a description that has been confirmed by participants in focus group discussions - and geocaching comes into view as a practice contextualising places in a very much similar way in certain circumstances.

This landscape of memory is holistic in the sense that, seen through the lens of practice theory, it is a phenomenon encompassing many parts: actions, people, things, and even feelings all contribute to that totality. In empirical geographies of memory, I suggest applying practice theory as a method to describe and analyse this landscape. By making use of this rigid vocabulary, the metaphorical imaginative geography of pastness can be grounded or "anchored" at the material geography of bunkers and other things from the past. In this perspective, Schatzki's terms allow for ethnographic data to be presented consistently and replace intuitions and metaphors of landscape as texts, arenas, and performances of memory (Dwyer, 2008, s.a.). A geography of memory carried out in this way accentuates the homogeneous production of localised memories I have identified as general understandings, while remaining open to ambiguous and even conflicting interpretations of the past at the same time. Landscapes of memory open up an interesting line of inquiry with a view to the heterogeneous totality of localised memories.

Acknowledgements. I would like to thank the two anonymous reviewers as well as Florian Dünckmann and Jonathan Everts for their comments on previous versions of this paper. This research has been funded by a grant by the German Research Foundation DFG (DU 415/4-1).

Edited by: B. Korf

Reviewed by: two anonymous referees

\section{References}

Alderman, D.: School Names as Cultural Arenas: The Naming of U.S. Public Schools after Martin Luther King, Jr., Urban Geography, 23, 601-626, 2002.

Assmann, J.: Communicative and Cultural Memory, in: Cultural Memories: The Geographical Point of View, edited by: Meusburger, P., Heffernan, M., and Wunder, E., Knowledge and Space, 4, Springer, Dordrecht, 15-28, 2011.

Azaryahu, M.: The power of commemorative street names, Environ. Plann. D, 14, 311-330, 1996.
Bayerisches Landesamt für Denkmalpflege (BLfD): Bayerischer Denkmalatlas: Aktennummer D-3-71-116-39, http://www.geoportal.bayern.de/bayernatlas/denkmal, last access: 6 August 2014.

Bennett, L.: Concrete multivalence: practising representation in bunkerology, Environ. Plann. D, 31, 502-521, 2013.

Bischoff, W. and Denzer, V.: Orte des Erinnerns und Vergessens aus geographischer Perspektive, Berichte zur deutschen Landeskunde, 83, 5-25, 2009.

Bourdieu, P.: Outline of a Theory of Practice, Cambridge University Press, Cambridge, 1977.

Confino, A.: Memory and the History of Mentalities, in: Cultural memory studies: An international and interdisciplinary handbook, edited by: Erll, A. and Nünning, A., Media and cultural memory, 8, de Gruyter, Berlin, 77-84, 2008.

Cosgrove, D. E.: Social Formation and Symbolic Landscape, With a new introduction, 2nd edn., Univ. of Wisconsin Press, Madison, Wis, 1998 [1984].

Crang, M. and Cook, I.: Doing Ethnographies, Sage, London, 2007.

Cresswell, T.: Landscape and the Obliteration of Practice, in: Handbook of Cultural Geography, edited by: Anderson, K., Domosh, M., Pile, S., and Thrift, N., Sage, London, 269-281, 2003.

DeLyser, D.: Authenticity on the Ground: Engaging the Past in a California Ghost Town, Ann. Assoc. Am. Geogr., 89, 602-632, 1999.

Department of the Army: Countermobility: FM 5-102, Washington, DC, 1985.

Dwyer, O. J. and Alderman, D. H.: Memorial landscapes: analytic questions and metaphors, GeoJournal, 73, 165-178, 2008.

Edensor, T.: The ghosts of industrial ruins: ordering and disordering memory in excessive space, Environ. Plann. D, 23, 829-849, 2005.

Erll, A.: Cultural Memory Studies: An Introduction, in: Cultural memory studies: An international and interdisciplinary handbook, edited by: Erll, A. and Nünning, A., Media and cultural memory, 8, de Gruyter, Berlin, 1-15, 2008.

Everts, J., Lahr-Kurten, M., and Watson, M.: Practice Matters!: Geographical inquiry and theories of practice, Erdkunde, 65, 323334, 2011.

Foote, K. E. and Azaryahu, M.: Towards a Geography of Memory: Geographical Dimensions of Public Memory and Commemoration, Journal of Political and Military Sociology, 35, 125-144, 2007.

Garrett, B.: Assaying history: creating temporal junctions through urban exploration, Environ. Plann. D, 29, 1048-1067, 2011.

Giddens, A.: The Constitution of Society. Outline of the Theory of Structuration, Polity, Cambridge, 1984.

Halbwachs, M.: The collective memory, Harper \& Row, New York, 1980 [1925].

Harrison, R.: Heritage. Critical approaches, Routledge, London, 2012.

Hitchings, R.: People can talk about their practices, Area, 44, 6167, 2012.

Hoelscher, S. and Alderman, D.: Memory and place: geographies of a critical relationship, Soc. Cult. Geogr., 5, 347-355, 2004.

Hoskins, G.: Lobotomizing Logics: A Critique of Memory Sports and the Business of Mapping the Mind, in: Palgrave Macmillan Memory Studies, edited by: Jones, O. and Garde-Hansen, J., Palgrave Macmillan, Basingstoke, 234-249, 2012. 
Hubel, A.: Denkmalpflege: Geschichte - Themen - Aufgaben. Eine Einführung, 2. Aufl., Reclam, Stuttgart, 2011.

Ingold, T.: The perception of the environment: Essays on livelihood, dwelling \& skill, Routledge, London, New York, 2000.

Johnson, N. C.: Locating Memory: Tracing the Trajectories of Remembrance, Historical Geography, 33, 165-179, 2005.

Jones, O. and Garde-Hansen, J. (Eds.): Geography and Memory: Explorations in Identity, Place and Becoming, Palgrave Macmillan Memory Studies, Palgrave Macmillan, Basingstoke, 2012.

Kaminsky, A. (Ed.): Orte des Erinnerns. Gedenkzeichen, Gedenkstätten und Museen zur Diktatur in SBZ und DDR, Bundeszentrale für Politische Bildung, Bonn, 2007.

Kansteiner, W.: Finding Meaning in Memory: A Methodological Critique of Collective Memory Studies, Hist. Theory, 41, 179197, 2002.

Legg, S.: Contesting and surviving memory: space, nation, and nostalgia in Les Lieux de Mémoire, Environ. Plann. D, 23, 481-504, 2005.

Legg, S.: Reviewing geographies of memory/forgetting, Environ. Plann. A, 39, 456-466, 2007.

Lowenthal, D.: Past Time, Present Place: Landscape and Memory, Geogr. Rev., 65, 1-36, 1975.

Maus, G.: Erinnerungslandschaften: Praktiken ortsbezogenen Erinnerns am Beispiel des Kalten Krieges, Kieler Geographische Schriften 127, Kiel, 2015.

Meusburger, P., Heffernan, M., and Wunder, E. (Eds.): Cultural Memories: The Geographical Point of View, Knowledge and Space, 4, Springer, Dordrecht, 2011.

Middleton, D. and Brown, S. D.: Memory and Space in the Work of Maurice Halbwachs, in: Cultural Memories: The Geographical Point of View, edited by: Meusburger, P., Heffernan, M., and Wunder, E., Knowledge and Space, 4, Springer, Dordrecht, 2950, 2011.

Mitchell, D.: Cultural landscapes: just landscapes or landscapes of justice, Prog. Hum. Geogr., 27, 787-796, 2003.

Nora, P.: Between Memory and History: Les Lieux de Mémoire, Representations, 26, 7-24, 1989.

Ogborn, M.: History, memory and the politics of landscape and space: work in historical geography from autumn 1994 to autumn 1995, Prog. Hum. Geogr., 20, 222-229, 1996.

O'Hara, K.: Understanding Geocaching Practices and Motivations, edited by: Burnett, M., Costabile, M., Catarci, T., de Ruyter, B., Tan, D., Czerwinski, M., and Lund, A.: Proceedings of the twenty-sixth annual SIGCHI conference on Human factors in computing systems, ACM Press, New York, 1177-1186, 2008.

Ongyerth, G.: Fortifikationen des Kalten Krieges - Methodische Bewertung eines sperrigen Themas, Die Denkmalpflege, 38-42, 2009.

Petermann, S.: Places and Spaces: The Remembrance of D-Day 1944 in Normandy, in: Cultural Memories: The Geographical Point of View, edited by: Meusburger, P., Heffernan, M., and Wunder, E., Knowledge and Space, 4, Springer, Dordrecht, 233248,2011
Reckwitz, A.: Toward a Theory of Social Practices: A development in culturalist theorizing, European Journal of Social Theory, 5, 245-265, 2002.

Rose-Redwood, R., Alderman, D., and Azaryahu, M.: Collective memory and the politics of urban space: an introduction, GeoJournal, 73, 161-164, 2008.

Schama, S.: Landscape and memory, Harper Perennial, London, 1995.

Schatzki, T.: Social practices: A Wittgensteinian approach to human activity and the social, Cambridge University Press, Cambridge, 1996.

Schatzki, T.: The Site of the Social: A Philosophical Account of the Constitution of Social Life and Change, Pennsylvania State University Press, University Park, 2002.

Schatzki, T.: Materiality and Social Life, Nature and Culture, 5, 123-149, 2010a.

Schatzki, T.: The Timespace of Human Activity: On Performance, Society, and History as Indeterminate Teleological Events, Toposophia: Sustainability, Dwelling, Design, Lexington Books, Lanham, Md., 2010b.

Schatzki, T.: Landscapes as Temporalspatial Phenomena, in: The Place of Landscape: Concepts, Contexts, Studies, edited by: Malpas, J., MIT Press, Cambridge, 65-89, 2011.

Schatzki, T.: A Primer on Practices: Theory and Research, in: Practice-Based Education: Perspectives and Strategies, edited by: Higgs, J., Barnett, R., Billett, S., Hutchings, M., and Trede, F., Practice, Education, Work and Society, 6, SensePublishers, Rotterdam, 13-26, 2012.

Schatzki, T.: Practice Theory as Flat Ontology, in: Praxistheorie: Ein soziologisches Forschungsprogramm, edited by: Schäfer, H., transcript, Bielefeld, http://www.transcript-verlag. de/978-3-8376-2404-5/praxistheorie, in press, 2015.

Schmidt, R. and Volbers, J.: Siting Praxeology. The Methodological Significance of "Public" in Theories of Social Practices, J. Theor Soc. Behav., 41, 419-440, 2011.

Thrift, N.: Non-Representational Theory Space, Politics, Affect, Routledge, London, 2008.

Till, K. E.: Places of Memory, in: A Companion to Political Geography, edited by: Agnew, J., Mitchell, K., and Ó Tuathail, G., Blackwell, Malden, MA, 289-301, 2003.

Wylie, J.: Landscape, Key ideas in geography, Routledge, London, 2007. Zeitler, E.: Making Places, Molding Memories: Political and Race-based Origins of Monuments, Memories, and Identities, Historical Geography, 37, 22-25, 2009. 